\title{
BIOLOGICAL CONTROL IN THE GREEN OASIS
}

\author{
J.K. WAAGE \\ Director, International Institute of Biological Control \\ President, International Organization of Biological Control, \\ Silwood Park, Berks. SL5 7TA, United Kingdom
}

\begin{abstract}
Biological control, the use of living organisms as pest control agents, is emerging as an important component of pest management programmes world-wide. Biological control has a long history as a public sector activity, characterised by government programmes on control of alien pests and on government and university research to develop Integrated Pest Management (IPM) packages based on natural enemy conservation. Biological control now has a growing place in the private sector, as biological control products and services fill niches where chemical control is no longer desirable.

Beyond its contribution to the technology of pest management, biological control has a compelling social message for agricultural and environmental development, emphasising minimal intervention, natural processes and sustainability. This message is now helping to revolutionise systems for extension of pest management and conservation of natural habitats.

New Zealand combines several features which make it a particularly important and challenging environment for biological control. Firstly, it has an intensely international agricultural trade, with associated needs to avoid and manage alien pests and to maintain high quality of exported produce. Secondly, it has a highly unique flora and fauna, which generates a demand for management of alien invasive pests of natural habitats and a strong concern for the ecological effects of introduction of biological control agents across all ecosystems. Finally, it has a substantial number of important, indigenous pests such as grass grubs, moths and leafrollers which has stimulated development of local biological control products. These features have resulted in New Zealand becoming a world leader in regulation, research and implementation of biological control technologies for agricultural and natural habitats. In examining the future of biological control, I will therefore emphasise these aspects which are of particular relevance to New Zealand.

Increase in global trade under GATT has already resulted in a perceptible rise in the number of alien pest problems, attributable not just to volume but to new trade routes, particularly the North-South trade in horticultural produce and the opening of China and the former USSR to trade in forestry products. This has increased interest in biological control and some countries like the USA have responded with rapid programmes of unprecedented scale, particularly against horticultural pests. New alien pests create increasing opportunities for non-tariff trade barriers, in which biological control may not seem at first a promising approach, as it may leave pest populations at cosmetically unacceptable levels on exported produce. However, with falling minimum residue levels for pesticides on exported produce, biological control will increasingly underpin export agriculture. Even more rapid growth is seen in biological control of alien pests of conservation, particularly weeds, where biological control is often the least disruptive and most cost effective control approach in extensive natural areas. Alien invasive species are recognised today as second only to habitat destruction as a cause of biodiversity loss, and signatories to the Convention on Biological Diversity are obliged to manage them.

The key issues affecting biological control introductions today are their scientific performance and their safety. For new pest problems in particular, biological control projects have very high start-up costs, long duration and only moderate probabilities of success set, of course, against enormous long term economies where agents succeed. With falling public sector funding and a growing number of targets, ecological research
\end{abstract}

Proc. 50th N.Z. Plant Protection Conf. 1997: 143-145 
is of increasing value in the prediction of success and acceleration of programmes. Ecological research is also essential to the expansion of safety studies required before introduction of agents. Biological control has grown in an agricultural tradition where "risk" has meant risk to agriculture, but emphasis is now shifting towards impact on the environment and non-target species. Biological control has an impressive safety record, but little tradition of environmental impact assessment. A new international Code of Conduct for biological control and new national procedures for regulation and consensus building underpin a growing emphasis on biocontrol safety. The most significant issues here are biological control for conservation, where issues of risk and success converge conveniently, and commercial biological control. In the latter case, predators, parasites and pathogens introduced as commercial products are not always recognised as alien introductions. Because they are generally less specific than introductions for "classical biological control" and imported through private rather than public agencies, they deserve particular attention. Use of local species for this commercial biological control is desirable. This approach has been stimulated in New Zealand by the importance of unique, native pest species.

Commercial biological control today has established niche markets in the horticultural sector and in some environmentally sensitive areas (e.g. waterways, forests) where the relatively high prices of products like microbial formulations, nematodes and insect predators and parasitoids can be accommodated and minimising chemical pesticide use is encouraged. For all this, biological control products constitute less than $1 \%$ of a $\$ 30$ b industry, most of this comprising sales of Bacillus thuringiensis by a shrinking number of companies. The growth of biological control products is unsatisfactory relative to demand, and new niche markets created by pesticide restrictions or decisions not to reregister products, particularly in minor crops, are not being serviced by new biological control technologies. This may reflect how biological control products have been developed by their major investors, the multinational agrochemical industry and the biotechnology industry. The former have experimented with biological control products but have generally found their use too complex and their markets too small to compete with internal chemical products. For biotechnology companies, the performance of engineered bacterial and viral pest control products have not justified the venture capital invested in them, but they have helped these companies with their secondary objective of developing technology to direct at more lucrative products such as transgenic plants. All this has meant that many biological control product initiatives have been aborted, much useful technology sits inaccessible on corporate shelves and there is little on the market.

There is a need to re-examine the appropriate industrial base for biological control. Small markets are a problem, particularly in small countries like New Zealand, but there are good models for small biological control businesses and products. We must also free biological control product development from the chemical pesticide paradigm which has marginalized their biological properties (e.g. reproduction, host finding) which are in fact their most competitive features. Tomorrow's biological control businesses will compete with new generation selective chemical pesticides and transgenic plants, and their success will depend a great deal on public perceptions of pesticides and biotechnology.

Biological control has found its way onto the farm and into the forest today as a component of IPM programmes, where it often provides the foundation which permits a strategy of reduced intervention with chemical or other products, lowering input costs, maintaining yields and reducing risks of pesticide-induced problems. In recent decades, IPM has had serious problems with successful implementation due in part to its knowledge-intensive nature and monitoring requirements, and in part to subsidy and aggressive marketing of chemical pesticides. IPM today is evolving along several paradigms. In the developed world, IPM is often seen as a predetermined package of methods focused on intervention, for extension to the farmer. In the developing world, it is often a more ecological process based on local appreciation of natural biological control and use of intervention as a last resort, reflecting sensitivity to a history of disasters associated with over-reliance on chemicals. The tropical experience has engendered a successful participatory approach to IPM implementation called the Farmer Field School 
which extends competence in biological control beyond scientists to farmers and political leaders. In developed countries, there is a growing trend for IPM extension to farmers to be driven by commodity boards or, in some cases, even the retail food industry, which can require farmers to apply IPM packages as a condition for purchase of their produce. While this is making IPM happen where it has not before, and is introducing biological control rapidly to millions of consumers, the North has something to learn from the South about farmer empowerment and public participation in IPM and biological control.

New Zealand's particular needs for management of alien and indigenous species and for environmental protection make it an important player in future development of biological control. Stimulated by these challenges, New Zealand has generated an impressive level of research and an unrivalled level of involvement of the general public in both financing and making decisions about biological control. This capability and commitment is a great asset in highly competitive and increasingly green international export markets, where biological control can help to create market advantage through pesticide-free produce and production systems.

Keywords: biological control, integrated pest management 